\title{
A Educação Interprofissional na Formação em Psicologia: Olhares de Estudantes
}

The Interprofessional Education in Educational Psychology: Student's Perspectives

La Educación Interprofesional en la Formación en Psicología: Visión de los Estudiantes

Thamires da Silva Souto, Sylvia Helena Batista \& Nildo Alves Batista

Universidade Federal de São Paulo
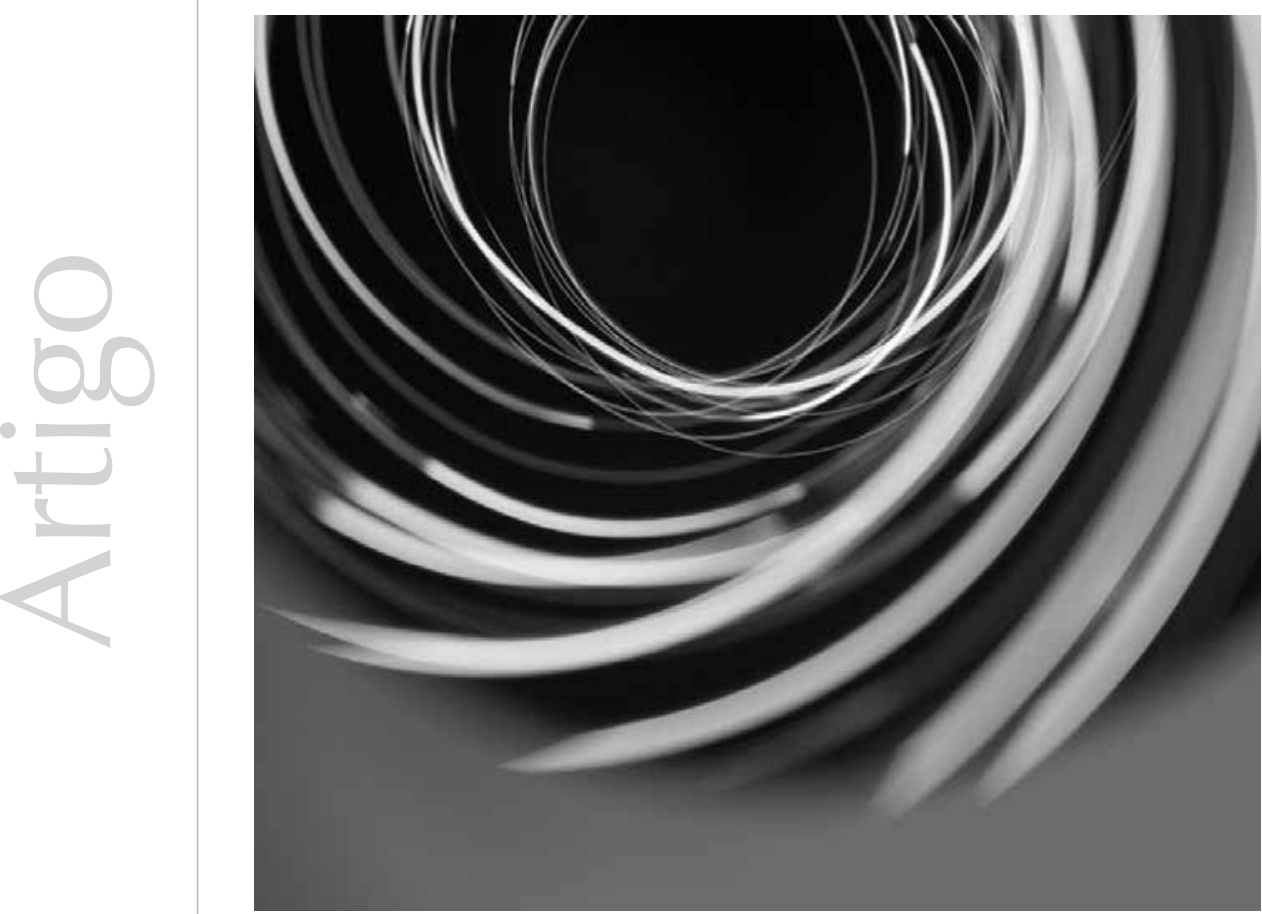
Resumo: Em meio a um cenário de discussão entre os atuais currículos de graduação de Psicologia e as experiências práticas desenvolvidas no contexto do SUS, entende-se a educação interprofissional como uma proposta de transformar a educação de futuros profissionais de saúde bem como de promover uma mudança na cultura dos cuidados em saúde. Nesse sentido, o objetivo do artigo é investigar a proposta de educação interprofissional do Projeto Político Pedagógico do campus Baixada Santista da UNIFESP no tocante à formação em Psicologia. A pesquisa foi realizada com abordagem quali-quantitativa, utilizando-se questionário RIPLS e análise de dados secundários. Esta última, em diálogo com os resultados do questionário, revela que os estudantes reconhecem a importância da educação interprofissional na graduação do psicólogo para o trabalho em equipe, concepção construída de forma articulada e multirreferenciada à concepção de educação interprofissional (EIP) que apresentam bem como ao reconhecimento do reforço da identidade profissional pela proposta de EIP. Apreendeu-se a relevância da educação interprofissional na graduação em Psicologia no preparo do psicólogo para o cuidado em saúde, uma vez que potencializa o desenvolvimento de competências referentes a práticas colaborativas, à comunicação interprofissional e ao cuidado com o sujeito na perspectiva da integralidade.

Palavras-chave: Formação do psicólogo. Educação superior. Profissionais da saúde. Estudantes universitários.

Abstract: Regarding the current discussions on the undergraduate curriculum in Psychology and the practical experience developed in the context of SUS (Unique Health System), the interprofessional education (IPE) is a proposal to transform future health professionals' education and to promote a change in the health care culture. In this sense, the aim of this study is to analyze the interprofessional education proposal of the Pedagogical Political Project at the campus Baixada Santista - UNIFESP as regards the educational psychology. This is a qualitative and quantitative research that used the Readiness for Interprofessional Learning Scale (RIPLS) and secondary data analysis. The study of the secondary data when analyzing the results of the questionnaire revealed that students recognized the importance of interprofessional education for the psychologist's education in the teamwork, this concept built in the field of interprofessional education, and the need to reinforce their professional identity by the proposed interprofessional pedagogical teaching. The relevance of interprofessional education in the undergraduation course of Psychology for health care was acknowledged considering that it improves the competencies related to collaborative practices, interprofessional communication and care to the individual in the integrative perspective. Keywords: Educational psychology. Higher education. Health professionals. College students.

Resumen: En medio a un escenario de discusión entre los actuales currículos de graduación de Psicología y las experiencias prácticas desarrolladas en el contexto del SUS (Sistema Único de Salud), se entiende la educación interprofesional como una propuesta de transformar la educación de futuros profesionales de salud así como de promover un cambio en la cultura de los cuidados en salud. En ese sentido, el objetivo del artículo es investigar la propuesta de educación interprofesional del Proyecto Político Pedagógico del campus Baixada Santista de la UNIFESP en lo que respecta a la formación en Psicología. La investigación fue realizada con un abordaje cuali-cuantitativo, utilizándose un cuestionario RIPLS y análisis de datos secundarios. Esta última, en diálogo con los resultados del cuestionario, revela que los estudiantes reconocen la importancia de la educación interprofesional en la graduación del psicólogo para el trabajo en equipo, concepción construida de forma articulada y multirreferenciada a la concepción de educación interprofesional (EIP) que presentan así como al reconocimiento del refuerzo de la identidad profesional por la propuesta de EIP. Se aprehendió la relevancia de la educación interprofesional en la graduación en Psicología en la preparación del psicólogo para el cuidado en la salud, ya que potencia el desarrollo de capacidades referentes a prácticas colaborativas, a la comunicación interprofesional y al cuidado con el sujeto en la perspectiva de la integralidad.

Palabras clave: Formación del psicólogo. Educación superior. Professionales de la salud. Estudiantes universitários.

A implantação do Sistema Único de Saúde (SUS), em 1988, contribuiu signficativamente para a identificação da necessidade de mudanças nos currículos de graduação das profissões de saúde no tocante ao preparo para uma atuação profissional comprometida com a integralidade do cuidado, com uma concepção ampliada de saúde e com o trabalho em equipe. Nesse sentido, de acordo com Spink, Bernardes e Mengon (2006), muitas propostas para a reorientação dos projetos pedagógicos de formação vêm sendo levantadas e apoiadas pelo Ministério da Saúde. 
A Psicologia apresenta uma inserção recente no campo da saúde no Brasil, visto que os psicólogos somente no início dos anos 80 passaram a atuar nas Unidades Básicas de Saúde, conforme parecer CNE/CES no 67/2003 (Brasil, 2003). Tendo esse fato em vista, os currículos de Psicologia vêm discutindo essa inserção na área da saúde. O Ministério da Saúde adverte para a necessidade de formar profissionais atentos à realidade do País e ressalta a importância do investimento na formação que prepara o psicólogo para a atuação no SUS, sem deixar de lado as outras especificidades da profissão. Entretanto, fica claro que, mesmo com as novas exigências estabelecidas, a realidade é que muitos processos de formação ainda estão fundamentados no modelo biomédico, nos seus limites e paradigmas, o que traz como consequência a formação de um estudante não adequadamente preparado para a prática na realidade do SUS (Mângia, 2009).

A educação interprofissional (EIP) tem sido vista como proposta disparadora de mudança nesse cenário de discussões entre formação e prática profissional. Em 1978, a educação interprofissional foi reconhecida pela primeira vez pela Organização Mundial da Saúde (OMS) como ferramenta fundamental para o cuidado em saúde (World Health Organization, 1978).

De acordo com documento apresentado pela OMS em 1988, denominado Learning Together to Work Together for Health, entende-se a educação interprofissional como uma oportunidade de se considerar os meios tradicionais de cuidado à saúde, no intuito de não promover mudanças apenas no que diz respeito às práticas educacionais, mas em um âmbito muito maior: a mudança na cultura dos cuidados de saúde (World Health Organization, 1988).
Entretanto, as propostas presentes nesse documento dizem muito mais respeito à formação em geral, como experiências pontuais na graduação, cursos de pósgraduação e especializações bem como o aprendizado interprofissional na prática, também ressaltando algumas políticas educacionais e de saúde - diferentemente do que pretendemos focar neste estudo.

O Center for the Advancement of Interprofessional Education (CAIPE, Londres) acredita que a educação interprofissional se realiza no momento em que uma ou mais profissões aprendem "com, para e sobre cada uma" com a finalidade de melhorar a comunicação, a colaboração interprofissional e, como consequência, a qualidade do cuidado (CAIPE, 2007). Os principais objetivos desse modelo de educação consistem na modificação de atitudes e de percepções dos profissionais da equipe interdisciplinar, de forma a melhorar a comunicação a partir da construção de relações mais abertas e dialógicas, reforçar a competência colaborativa bem como integrar o profissional especialista na perspectiva da integralidade no cuidado. Esses objetivos visam ao aprendizado, por parte dos alunos, das três competências no âmbito do trabalho em equipe: a competência comum a todos os profissionais de saúde, a competência específica de cada profissão e a competência colaborativa, essencial para o trabalho conjunto (Barr, 1998).

Nesse sentido, na área da formação em saúde, a educação interprofissional é vista como um componente crucial não só pela proposta de aprendizagem compartilhada mas também por ser disparador de novos tipos de trabalho e de novas formas de subjetivação dos papéis profissionais, uma vez que reorganiza os fluxos de tarefas e responsabilidades no contexto da equipe interprofissional (Levison, 2003).

Mesmo sendo considerada uma potência em 
vários países do mundo no que diz respeito ao preparo para a prática em saúde (CAIPE, 2007), ainda não há evidências quanto à sua eficácia em nível de graduação. Na revisão realizada para este estudo, o que se observa são experiências pontuais e de curta duração de treinamentos, incluindo estudantes de Psicologia, juntamente a estudantes de outras áreas da saúde, mostrando os benefícios da educacão interprofissional no preparo para o trabalho em equipe e, em consequência, para a integralidade no cuidado (Robinson, Church, \& Goodwin, 2009; Howell, 2009; Champion $\&$ Hayward, 2006). Nenhum relato menciona o desenvolvimento de um projeto político pedagógico (PPP) de graduação inteiramente baseado nos princípios colaborativos da educação interprofissional de cursos na área de saúde, incluindo a Psicologia.

O PPP do Curso de Psicologia do campus Baixada Santista/UNIFESP assume, entre os seus princípios direcionadores, a educação interprofissional. Essa proposta insere-se em um projeto maior com outros cinco cursos de graduação (Educação Física, Fisioterapia, Nutrição, Serviço Social e Terapia Ocupacional), que tem como objetivo central a formação de profissionais da saúde para a atuação em equipe interprofissional, dando ênfase à integralidade no cuidado, à formação técnico-científica e humana de atuação em saúde e à formação científica, que entende a pesquisa como propulsora do ensino e da aprendizagem; o projeto, no entanto, enfatiza a consistência da formação profissional do psicólogo.

Para atingir tais objetivos, o curso é estruturado em eixos formativos que consistem em caminhos a serem trilhados pelos estudantes de Psicologia com vistas ao perfil final desejado para o egresso. Os eixos mencionados são: o ser humano e sua inserção social (200 horas), o ser humano em sua dimensão biológica ( 680 horas), trabalho em saúde (360 horas) e o eixo específico -
Psicologia (4.065 horas). Os três primeiros são desenvolvidos em turmas mistas (integrando os estudantes de todos os cursos), e o último é direcionado especificamente aos estudantes de Psicologia. Em todos os eixos, as atividades são desenvolvidas por meio de módulos semestrais, que buscam articular diferentes olhares disciplinares na perspectiva de superar o currículo centrado em disciplinas.

No curso de Psicologia, os três primeiros anos são constituídos por módulos de todos os eixos, e os dois últimos anos apresentam-se compostos por módulos referentes ao eixo específico, incluindo os estágios curriculares. Vale realçar que a interprofissionalidade se mantém na medida em que as experiências de aprendizagem em diferentes módulos de estágios podem ser compartilhadas com estudantes de outros cursos.

Essa organização curricular dá prioridade às discussões e às vivências conjuntas da Psicologia com as outras cinco profissões envolvidas nesse percurso formativo. $\mathrm{O}$ ensino é visto como indissociável da pesquisa e da extensão: a pesquisa encontra campo fecundo de investigação na extensão e no próprio ensino, possibilitando novas dimensões para a formação ao aproximar os estudantes da realidade local e regional e ao alimentar a construção de novos conhecimentos nos projetos de pesquisa.

O projeto pedagógico, conforme referido, desenvolve-se articulando os quatro eixos, e estes são "orientados pela formação de profissionais da saúde comprometidos com atuações consistentes, críticas e potencialmente transformadoras da realidade social" (Universidade Federal de São Paulo UNIFESP, 2006, p.53).

O eixo específico do curso de Psicologia considera todos os princípios, conteúdos e metodologias necessárias para a formação 
do psicólogo, tendo por referência as Diretrizes Curriculares Nacionais para o Curso de Psicologia (Brasil, 2004). Por outro lado, os outros três eixos anteriormente citados, além de construírem base para a formação específica, assumem o diferencial na formação ao propor ambientes conjuntos e aprendizagens compartilhadas entre os estudantes de Psicologia e os estudantes das outras áreas da saúde.

A imersão em classes mescladas no eixo $O$ ser humano em sua dimensão biológica, cuja experiência de integração entre estudantes não é habitual nos currículos tradicionais de Psicologia, objetiva uma compreensão diferenciada dos processos de adoecimento físico e consequente maior capacidade do diálogo do futuro psicólogo com as demais profissões da área da saúde.

Especialmente no eixo trabalho em saúde, os alunos, também reunidos em grupos interprofissionais, têm a oportunidade de conhecer a realidade de sua profissão em diferentes setores e níveis de atenção no SUS, o que contribui para a construção de sua identidade profissional. Essa aproximação aos cenários ocorre concomitantemente a um preparo teórico-conceitual sobre a prática no SUS, no qual o estudante constrói conhecimentos a respeito do processo de trabalho em saúde, das múltiplas dimensões envolvidas no processo saúde-doença e da produção de cuidado integral bem como da compreensão das diversas profissões e práticas de saúde, da realidade dessa área, das especificidades do sistema de saúde vigente em nosso país e dos diversos níveis de atenção à saúde, além das bases e da história do SUS. (UNIFESP, 2006).

Por sua vez, o eixo o ser humano e sua inserção social, ao abranger áreas como Antropologia, Sociologia, a própria Psicologia, Educação, Filosofia, ética/bioética e política, objetiva propiciar uma formação em saúde que compreenda a incorporação teórica e metodológica das contribuições das diferentes áreas do conhecimento das ciências humanas, oferecendo base fundamental para a formação dos estudantes de Psicologia.

Assumindo que "a ênfase interdisciplinar favorece o redimensionamento das relações entre diferentes conteúdos, contribuindo para que a fragmentação dos conhecimentos possa ser superada" (UNIFESP, 2006, p. 40), o profissional de Psicologia é formado por meio da integração de diversas áreas dos saberes, fundamental para a formação de um profissional que atue no SUS.

A partir do momento em que o aprendizado ocorre de maneira integrada, os alunos exercitam a prática permanente do diálogo interprofissional bem como o pensar em novas interações no trabalho em equipe. Espera-se, assim, que se desenvolvam posturas de respeito à diversidade e de cooperação, de modo a efetivar práticas transformadoras e parcerias na construção de projetos.

Esse modelo curricular de formação em Psicologia na graduação já vem formando turmas de aproximadamente 50 psicólogos por ano, tendo sido avaliado pelo Ministério da Educação (MEC) com nota 5.

O número de experiências e de pesquisas internacionais que objetivam investigar a educação interprofissional na formação em Psicologia ainda é muito reduzido, e, entre os poucos estudos, a maioria das investigações envolve alunos de pós-graduação em Psicologia com graduandos de outros cursos da saúde (Robinson, Church, \& Godwin, 2009; Howell, 2009; Champion \& Hayward, 2006).

Considerando essa experiência, questionase: como o estudante de Psicologia do campus Baixada Santista avalia a vivência 
de estratégias de educação interprofissional na graduação? Que competências essas estratégias desenvolvem no estudante ao final da graduação? Como o aprendizado específico para o trabalho em equipe e para a prática da integralidade no cuidado vem ocorrendo na graduação?

O objetivo desta pesquisa foi investigar a proposta de educação interprofissional do campus Baixada Santista da Universidade Federal de São Paulo no Projeto Pedagógico de Graduação em Psicologia, na perspectiva de estudantes do respectivo curso.

\section{Método}

O curso de Psicologia, implantado em 2006, tem entrada anual de 50 ingressantes e já formou duas turmas. Atualmente, contém 245 alunos (incluindo os cinco anos do curso) e 38 docentes (abrangendo os professores que atuam nos eixos comuns e nos módulos específicos do curso de Psicologia). Seu marco curricular, em consonância com o que determina e possibilita as DCNs, apresenta como ênfases a saúde e a pesquisa.

No processo de produção de dados, utilizaram-se dois instrumentos: o primeiro refere-se ao Questionário RIPLS (The Readiness for Interprofessional Learning Scale). A versão original da escala foi publicada por Parsell e Bligh (1999), e apresenta núcleos responsáveis por avaliar a relação entre a variável de prontidão para a aprendizagem interprofissional e alguns dos atributos necessários para o trabalho e a colaboração em equipe, a identidade profissional, as funções e as responsabilidades profissionais, o crescimento pessoal e as relações e os benefícios para os pacientes. Para este estudo, realizou-se uma adaptação da escala para o idioma português, visando a melhor apreender aquilo que se tem como objetivo desse questionário. Essa adaptação e validação foram frutos da pesquisa desenvolvida por Aguilar-da-Silva, Scapin e Batista (2011), que abrangeu também universitários, e que envolveu, além do idioma, adequações em relação às singularidades do sistema universitário brasileiro. Essa versão também foi utilizada por Landim, Silva e Batista (2012) em um estudo junto a residentes de Programa de Residência Multiprofissional em Saúde.

Com a adaptação, o questionário abrangeu 30 assertivas, divididas em quatro núcleos que visam a avaliar: (1) trabalho em equipe e efetiva colaboração com outros profissionais da saúde, (2) identidade profissional, (3) papéis e responsabilidades e (4) responsabilidade sobre o paciente.

Com o objetivo de avaliar as competências de educação interprofissional desenvolvidas nos estudantes ao final da graduação, foi aplicado o referido questionário aos 43 estudantes do quinto ano de Psicologia no ano 2010 (todos egressos da primeira turma de concluintes do curso). O convite à participação foi feita a todos os estudantes, e respeitou-se a adesão voluntária ao estudo. Desse universo, 22 estudantes preencharam o instrumento, número equivalente a pouco mais de $50 \%$ da população de estudo. Marconi e Lakatos (2003) comentam que a literatura indica validade nos dados com retorno de aproximadamente $25 \%$.

Os dados coletados nos questionários foram tabulados e expressos em percentis, e são apresentados em formatos de gráficos.

Como estratégia de aprofundamento na coleta de dados, o segundo instrumento compreendeu dados secundários a partir da análise de grupos focais já realizados em estudo anterior. Um desses grupos ocorreu com 10 alunos de diferentes anos do curso de Psicologia. Os tópicos que conduziram à discussão do grupo focal foram: 1) projeto pedagógico interprofissional (descrição e 
vantagens, impasses e desafios em sua implantação), 2) trabalho em equipe (como é trabalhado no ensino e como conceitos e práticas têm mudado ao longo do curso), 3) integralidade no cuidado (como é trabalhada no ensino e como conceitos e práticas têm mudado ao longo do curso).

Da transcrição dos grupos focais, analisaramse as falas dos estudantes pautando-se na análise temática (Minayo, 2007), a partir de três núcleos direcionadores: (1) importância da educação interprofissional para o trabalho em equipe na graduação do psicólogo, (2) concepção de educação interprofissional e (3) construção da identidade profissional em uma graduação em psicologia com enfoque na educação interprofissional. Os estudantes foram identificados como: PS1, PS2, PS3 e PS4 (alunos do 10 ano), PS5 e PS6 (alunos do $2^{\circ}$ ano), PS7 e PS8 (alunos do $3^{\circ}$ ano) e PS9 e PS10 (alunos do 4ㅇan ano).

As categorias emergentes da análise do grupo focal permitiram visualizar o processo de construção das concepções dos alunos do curso de Psicologia a respeito da contribuição da educação interprofissional no seu processo de graduação bem como das concepções relativas ao trabalho em equipe e à integralidade no cuidado, além de nos revelar como veem a construção de sua identidade profissional.

Foi estabelecido um diálogo entre tais resultados com aqueles obtidos a partir da aplicação do questionário RIPLS, privilegiando-se as dimensões 1, 2 e 3 (trabalho em equipe e efetiva colaboração com outros profissionais da saúde, identidade profissional (papéis e responsabilidades). A dimensão 4 (responsabilidade sobre o doente) não foi analisada no diálogo com o grupo focal.

A pesquisa foi aprovada pelo Comitê de Ética em Pesquisa da UNIFESP (processo no
1584/10), e todos os participantes assinaram o Termo de Consentimento Livre e Esclarecido.

\section{Resultados}

A partir da postura majoritariamente concordante dos egressos diante das assertivas "o aprendizado junto com outros estudantes irá me ajudar a tornar-me um membro efetivo de uma equipe de saúde" e "a aprendizagem compartilhada antes da formatura irá me ajudar a tornar-me melhor para o trabalho em equipe", depreende-se que os estudantes, ao final da graduação, reconhecem fortemente a importância da EIP na formação do psicólogo para o trabalho em equipe.

Ainda se pode destacar, entre os achados juntos aos egressos, o reconhecimento quanto à relevância de considerar o paciente uma pessoa que envolve todo um contexto de vida e não apenas seus problemas clínicos, o reconhecimento majoritário quanto à importância e os benefícios do trabalho em equipe e também a importância do aprendizado compartilhado para a futura prática profissional.

Esses dados dos egressos são reforçados pelo que disseram os estudantes dos outros anos da graduação, uma vez que, a partir da análise do grupo focal, foi unânime a percepção da importância da EIP na graduação em Psicologia:

- Eu conhecer mais o outro, eu saber os problemas que ele tem com a sua profissão, que eu vou ter (...) mais respeito e mais sinceridade com o outro, vou saber ouvir melhor (...) eu acho que facilita muito o trabalho assim. (PS1)

- A proposta é que todas as profissões, além de ter um olhar não tão especialista assim do corpo, tenham uma visão geral da pessoa, do seu contexto social, em conjunto com as outras profissões (...). (PS5) 
Essa percepção abrangeu diferentes categorias. Uma primeira destaca o reconhecimento da importância da equipe interprofissional:

- Desde o começo, assim eles (professores) deram grande importância pra essa coisa do trabalho em equipe interprofissional e, pelo menos até agora, eu continuo vendo a importância assim. (PS5)

A dimensão do aprender junto para trabalhar junto também emergiu:

- Tenho que aprender a conviver com as pessoas que estão lá, tenho que aprender com elas, ensinar pra elas, trocar, é certo pra trabalhar em equipe. (PS5)

A categoria preparo para a integralidade do cuidado mostrou-se bastante forte, desdobrando-se em subcategorias que abrangeram a concepção de clínica ampliada, preparo para os diferentes níveis de atenção, possibilidade de estudar o ser humano em todas as suas dimensões e possibilidade de entrar em contato com a realidade social da população:

- Tem que ver que o indivíduo é muito além daquilo, da sua área, ele tem a parte psicológica, ele tem a parte da família, a parte social, então você tem que estar sempre avaliando o indivíduo como um todo (...). (PS6)

- Essa visão que a gente tem de proteção, prevenção e promoção de saúde, com essa nossa formação,... é que vai conseguir fazer esse sistema andar mesmo... (PS3)

A percepção da importância da educação interprofissional também compreendeu as categorias de possibilidade de vivenciar confronto de ideias, de pontos de vista e de diferentes saberes, de aprender a lidar com as diferenças, possibilidade de aprendizado com docentes de diferentes especialidades, possibilidade de vivenciar situações de demandas inusitadas e diversas, possibilidade de diálogo e de interação com outras áreas profissionais, conhecimento sobre os desafios das demais práticas e oportunidade de conhecer sobre outras habilidades e práticas profissionais:

- Tem iniciação com epilepsia e tem aluno da psico e da bio fazendo iniciação sobre o mesmo tema; os alunos se interessam também sobre outros assuntos que não só voltados especificamente para a área deles. (PS3)

- Você aprende a fazer trabalho de outra forma, você lida com as adversidades(...), você acaba se agrupando não com as pessoas só do curso mas com as pessoas que você se dá melhor, mesmo que sejam de outros cursos. (PS5)

- Cada professor é formado numa área (eixo comum); tem professor que é antropólogo, um é psicólogo, outro é da parte de Sociologia, então, tipo, cada um tem uma experiência de vida, um conteúdo diferente, é superinteressante (...). (PS6)

Esses dados sinalizam que a proposta de educação interprofissional na graduação em Psicologia na UNIFESP Baixada Santista favorece essas competências colaborativas para os alunos, preparando-os para o trabalho em equipe no contexto do SUS.

A partir da análise do grupo focal realizado, foi muito interessante perceber a emergência de diversas categorias no tocante a essa concepção de EIP, as quais configuram uma construção ao longo dos anos de graduação: concepção interdisciplinar e interprofissional do currículo, possibilidade de diálogo, troca de ideias com estudantes de outras profissões: preparo para um olhar ampliado sobre o ser humano, preparo para um olhar ampliado sobre uma situação de saúde, desenvolvimento da percepção da outra profissão como parceira fundamental para a prática:

- Vou saber ouvir melhor, vou saber passar 
alguma coisa de uma forma que talvez para ele vai ser mais simples ou, se não, a gente chega a algum consenso, a complexidade alcança os dois lados, eu acho que facilita muito o trabalho assim. (PS1)

- A gente tem matérias que são comuns a todos os cursos e que não são simplesmente matérias em comum, são matérias que a gente tem junto com pessoas dos outros cursos pra tentar fazer esse trabalho junto, assim. (PS5) - A gente muda o olhar que a gente tem daquela pessoa; se aquela pessoa viesse até a gente, ia olhar, e pelo que ela mostra, a gente não ia saber a situação, não que indo até lá a gente saiba tudo, mas aproxima bastante a gente da realidade. (PS6)

- Eles pedem para fazer o trabalho com uma pessoa de outro curso... (...) Eles incentivam então essa parte de interdisciplinaridade em todos os temas... (PS7)

A concepção sobre educação interprofissional expressou-se com força por meio da categoria aprendizado compartilhado com outras áreas profissionais, que traz como dimensões a interdisciplinaridade, a parceria, o diálogo e a troca de ideias com estudantes de diferentes profissões, olhar ampliado para o ser humano e sobre uma situação de saúde.

- Eu conhecer mais o outro, eu saber os problemas que ele tem com a sua profissão, que eu vou ter um olhar mais, com mais respeito e mais sinceridade com o outro (...). (PS1)

- (...) Quando a gente faz muito trabalho entre os diversos cursos, fazendo grupos para pensar nos trabalhos, a gente consegue explorar as várias visões dos profissionais, frente a frente, mesmo. (PS3)

- Isso aumenta as opções da gente, eu acho muito legal as classes serem misturadas, tipo assim, só uma turma durante 5 anos, eu acho que a gente perderia, e, por serem mais, eu acho que a gente ganha, conhece outros olhares (...). (PS5)
Ainda foi possível apreender a dimensão relativa ao espaço físico comum e compartilhado por estudantes de todos os cursos e à formação mais rica por conhecer outras profissões:

- Uma coisa significativa (para a integração dos alunos), o espaço físico, porque realmente a gente compartilhava o mesmo espaço também. (PS7)

Os dados representam a construção dos alunos acerca da concepção de educação interprofissional, de forma a ser possível traçar um paralelo entre os resultados desses dois núcleos, visualizando que a concepção de educação interprofissional e a percepção de sua importância para o preparo do psicólogo para o trabalho em equipe na graduação foram construídas e desenvolvidas de maneira articulada e multirreferenciada ao longo da graduação.

Entre os resultados obtidos pela aplicação do questionário RIPLS aos alunos egressos, foi interessante notar a unanimidade na constatação de que, ao final da graduação, o estudante sai da universidade com a concepção de que sua identidade profissional fora reforçada pela graduação cursada dentro da proposta. Diante da discordância frente à assertiva: "Há pouca sobreposição entre as minhas funções e a de outros estudantes da área da saúde", os alunos egressos revelam reconhecer de maneira positiva que sua prática é transversalizada pelas outras áreas da saúde.

Esse reconhecimento é de grande relevância para a futura prática profissional nessa área, visto que traz como consequência positiva a formação de um profissional que compreende que sua prática não é mais importante que a do outro, mas que devem ser intersectadas para garantir e oferecer um melhor cuidado em saúde. 
Os egressos do curso de Psicologia da UNIFESP Baixada Santista formaram-se em meio a esse modo de pensar. Nesse sentido, majoritariamente discordam das assertivas: "Sentir-me-ia desconfortável caso um outro estudante da área da saúde soubesse mais do que eu sobre um determinado tema" e "Eu devo adquirir muito mais competências e conhecimentos do que outros estudantes da área da saúde".

A unanimidade das respostas concordantes diante da afirmação: "A aprendizagem compartilhada vai me ajudar a entender as minhas próprias limitações" também reforça sua identidade profissional como psicólogo.

A análise do quarto grupo focal também permitiu a apreensão do reforço da identidade profissional pela EIP:

- A gente sai da nossa especialidade (...) então é como se fosse mais de uma graduação em uma só. (P6)

- Reconhecer que a minha prática não está sozinha lá, que ela está atravessada tanto por outros cursos daqui do campus quanto outros, assistência social, Medicina inclusive... (P10)

As categorias emergentes abrangeram: reconhecimento das interfaces entre a prática da Psicologia e a de outras profissões da saúde, outra profissão vista como essencial para o trabalho em equipe e respeito/reconhecimento pelas habilidades específicas dos demais profissionais:

- Vai ser muito interessante essa nossa multiprofissionalidade é no diagnóstico (...) O psicólogo vai e dá o diagnóstico dele, aí vem o fisio e já fala a parte dele. (P3)

- Você não fica mais: 'Vou jogar essa pessoa para tal lugar', (...) não, você tem um tratamento, como eu conheço dessa outra pessoa trabalhando junto, a gente troca informação (...). (PS4)
- Aí você começa a trabalhar e começa a ver como é importante ter pessoas de outras... Começa a ver: 'Nossa, se tivesse um fisio ou um TO aqui, como ia ser importante!' (PS9) Os resultados apresentados permitem inferir que a identidade profissional parece ser reforçada pela proposta de graduação em Psicologia com enfoque na educação interprofissional.

\section{Discussão}

Os resultados revelam, primeiramente, a percepção da importância da educação interprofissional para o preparo do psicólogo no trabalho em equipe na graduação, em relação ao qual é válido discutir a relevância do reconhecimento da equipe interprofissional por parte dos alunos. Após um primeiro estranhamento frente à proposta inovadora de graduação, o aluno tem, ao longo do currículo, diversas oportunidades de aproximação à prática em equipe interprofissional, tanto de maneira teórica, estudando tal relevância para o atendimento no SUS, quanto de maneira prática, aproximando-se aos possíveis cenários de atuação no cuidado em saúde desde o primeiro ano. Formar-se dentro de uma proposta de educação interprofissional pressupõe o reconhecimento da relevância do projeto para sua formação como profissional da saúde bem como das competências que essa formação lhe garantirá.

Destacando como primeiro objetivo do Projeto Político-Pedagógico da UNIFESP Baixada Santista a "formação de um profissional da área da saúde apto para o trabalho em equipe interprofissional, com ênfase na integralidade no cuidado ao paciente" (UNIFESP 2006, p.49), ao reconhecer a importância da prática em equipe interprofissional, o estudante reconhece a importância da EIP para esse preparo, que proporciona ao aluno a aprendizagem de ações coordenadas e de atitudes colaborativas, de forma a enfatizar uma formação profissional mais generalista, 
A concepção de integralidade do cuidado que fundamenta a política do SUS consiste, conforme Severo e Seminotti, em um "processo de trabalho que compreende a construção de uma política pública traduzida como um sistema co-operativo entre sujeitos trabalhadores, gestores e usuários na realização de diretrizes e de ações coletivas organizadas por lógicas voltadas para a garantia dos direitos sociais" (2010, p. 1.686). o que pode contribuir para uma prática mais coerente no SUS.

Segundo Barr (1998), as competências colaborativas possibilitam estabelecer claramente o papel e as responsabilidades de cada profissão, respeitando as competências e as limitações do próprio papel. Trabalhar em interação com outras profissões em diversos tipos de serviços implica saber lidar com as diferenças entre as profissões, investindo na integração da equipe e na identificação e compreensão das preocupações dos outros profissionais quanto ao cuidado com o paciente.

Segundo McNair (2005), aprender junto sobre o trabalho em saúde implica um fazer junto no cotidiano do cuidado em saúde. Ao adotar uma postura de cooperação/ colaboração em detrimento da competição e da concorrência, os profissionais se tornam aliados e desenvolvem entre si uma relação de respeito mútuo.

De acordo com Benevides (2005), a verdadeira contribuição da atuação do psicólogo no SUS está na conexão entre três princípios. O princípio da inseparabilidade busca a compreensão da subjetividade como processo coletivo de produção, devendo o psicólogo explorar a dimensão do SUS como política pública, como forma coletiva de produção das singularidades. O segundo princípio, autonomia e corresponsabilidade, visa à dedicação do profissional no que diz respeito a produzir saúde para a população, e responsabiliza o sujeito como autor e ator de sua própria vida, considerando os processos de objetivação e de subjetivação que decorrem ao longo de sua história. O terceiro e último, o princípio da transversalidade ou integralidade, constitui-se na intercessão da Psicologia com outros saberes/poderes/ disciplinas, a fim de contribuir para as possibilidades de uma nova saúde.
A reflexão sobre o trabalho do psicólogo no SUS e seus dispositivos de prática é essencial, visto que os princípios de universalidade, equidade e integralidade, premissas básicas do Sistema Único de Saúde, dependem da criação de alternativas que visem a redimensionar as políticas de saúde, transformandos princípios em práticas, em uma perspectiva que considera a saúde de forma integral. Acredita-se, com este estudo, que a proposta de educação interprofissional possa ser instrumento articulador que promoverá essas mudanças no tocante à prática do psicólogo no SUS.

A concepção de integralidade do cuidado que fundamenta a política do SUS consiste, conforme Severo e Seminotti, em um "processo de trabalho que compreende a construção de uma política pública traduzida como um sistema co-operativo entre sujeitos trabalhadores, gestores e usuários na realização de diretrizes e de ações coletivas organizadas por lógicas voltadas para a garantia dos direitos sociais" (2010, p. 1.686). Dessa maneira, a integralidade, como conceito fundamental da organização do nosso sistema de saúde, pressupõe uma organização da prática profissional, do processo de trabalho e da política pública em saúde.

Pensando nessa articulação com um currículo que também traz como importância fundamental a integralidade do cuidado, acredita-se que os profissionais formados com a proposta de graduação em Psicologia da UNIFESP Baixada Santista possam estar mais preparados para atender as demandas dos usuários do SUS.

Identifica-se que a formação em Psicologia no campus Baixada Santista está orientada por uma concepção de clínica ampliada, de acordo com a visão de Campos e Amaral:

A clínica ampliada baseia-se na construção de responsabilidade singular e de vínculo 
Relacionar-se com um novo grupo sempre gera uma ansiedade quanto à própria identidade (Guirado, 1987), estável entre equipe de saúde e paciente. $\mathrm{O}$ contato esporádico e vertical de diferentes profissionais sem um coordenador para cada caso tem acarretado inúmeros transtornos à eficácia e eficiência dos processos terapêuticos (p. 2007, p.855)

Os dados parecem mostrar que participar de uma formação que privilegia a integralidade do cuidado, dentro da concepção de clínica ampliada (conforme assumida acima), potencializa as competências colaborativas do futuro psicólogo para a prática em equipe, visto que a aprendizagem compartilhada inverte a lógica da tradicional formação em saúde e prepara para uma prática clínica que englobe as diversas visões profissionais, a partir de um diálogo entre os profissionais e gestores do SUS, visando à melhoria da qualidade do cuidado ao usuário.

Após a apresentação dos resultados obtidos com os alunos egressos e a partir da análise do grupo focal, podemos identificar uma percepção positiva dos estudantes em relação à proposta de educação interprofissional na graduação em Psicologia na UNIFESP Baixada Santista.

Em relação à identidade profissional, que aparece reforçada pela graduação em Psicologia com enfoque na EIP, novamente o aprendizado compartilhado emerge como importante para os futuros relacionamentos desses profissionais de saúde.

Relacionar-se com um novo grupo sempre gera uma ansiedade quanto à própria identidade (Guirado, 1987), e, nesse sentido, relevante é a vivência dessa ansiedade dentro do período de graduação bem como a identificação com os profissionais de outras áreas da saúde.

A exposição a experiências e vivências compartilhadas e o desenvolvimento das competências colaborativas ao longo da graduação contribuem para a formação de um profissional com maior clareza sobre seu papel, suas responsabilidades e competências dentro da equipe interprofissional. A proposta de educaçao interprofissional parece auxiliar na perspectiva de formar sujeitos em constante construção e reforço de sua identidade profissional. Esta reflete sempre o movimento de nossa prática, de nossa realidade. A prática em interface com outras profissões reforça essa identidade tendo em vista a construção de uma prática desafiadora em que nós, psicólogos, somos capazes de nos identificar e de acompanhar "o movimento dessas necessidades, sendo capazes de construirmos, sempre e permanentemente, respostas técnicas e científicas" (Bock, 1999, p.328).

Nesse contexto, compreende-se a identidade profissional como um processo que integra

fatores pessoais e de formação profissional que passam pela questão da escolha da Psicologia como profissão e o significado de ser psicólogo, a formação acadêmica e a vivência como profissional (Mazer \& Melo-Silva, 2010, p. 292)

Ao entender a proposta de educação interprofissional como disparadora de processos de mudanças da graduação em articulação com as demandas atuais dos serviços de saúde, apreende-se que a identidade profissional de psicólogo constitui um dos processos disparadores para essa prática em equipe, que considera a saúde de maneira ampliada e no cuidado do sujeito de forma integral (Abdalla, Batista, \& Batista, 2008).

\section{Conclusões}

Esta pesquisa permite situar que a proposta de educação interprofissional é de grande relevância na graduação em Psicologia, formando para o trabalho em equipe, uma vez que possibilita o desenvolvimento de competências colaborativas, de comunicação interprofissional e o cuidado do sujeito 
de maneira integral e contextualizada, coadunadas com as premissas e os princípios do Sistema Único de Saúde.

O processo de construção do conceito de educação interprofissional entre os estudantes de todos os anos do curso de Psicologia desvelou-se como processo complexo e multideterminado: primeiramente, entendendo a concepção interdisciplinar e interprofissional do currículo, depois percebendo a proposta no tocante ao preparo para o olhar ampliado sobre o sujeito e sobre uma situação de saúde, bem como desenvolvendo a percepção da educação interprofissional como possibilidade de diálogo e de interação com estudantes de outras áreas profissionais e de aprendizado compartilhado.

Foi possível sublinhar o papel da educação interprofissional no processo de construção da identidade profissional do psicólogo, entendendo que a identidade profissional está em contínua construção e acompanha a realidade social e contextual das múltiplas práticas.
Ferreira Neto (2010), Spink et al. (2006) e Benevides (2005), a partir de seus estudos, permitem identificar que grande parte dos projetos político-pedagógicos de graduação das universidades ainda permanece pouco integrada com a realidade dos serviços, trazendo como consequência a formação de profissionais despreparados para a prática segundo as premissas básicas do SUS. Nesse sentido, a proposta de educação interprofissional na graduação em Psicologia na UNIFESP Baixada Santista constitui parte importante de todo um movimento de redirecionamento da formação tradicional, questionando modelos e valores que devem ser reconstruídos, de forma a integrar a formação com a realidade dos serviços de saúde, construindo situações de aprendizagem que envolvem diferentes profissionais necessários para o trabalho em equipe na saúde.

Espera-se, com este artigo, contribuir com a literatura nacional e a internacional referente à temática da educação interprofissional em geral, e principalmente à relacionada com a formação em Psicologia, com vistas à atuação do psicólogo na área da saúde.

Thamires da Silva Souto

Graduada em Psicologia e residente do programa de Residência Multiprofissional em Saúde da Universidade Federal de São Paulo, São Paulo - SP - Brasil.

E-mail: sethaaamiii@hotmail.com

Sylvia Helena Batista

Doutora em Psicologia da Educação pela Pontifícia Universidade Católica de São Paulo e docente da Universidade Federal de São Paulo, São Paulo - SP - Brasil.

E-mail: sylvia.batista@unifesp.br

Nildo Alves Batista

Doutor em Medicina pela Universidade Federal de São Paulo e docente da Universidade Federal de São Paulo, São Paulo $\mathrm{SP}$ - Brasil.

E-mail: nbatista@unifesp.br

Endereço para envio de correspondência:

Rua Maracá, 266, ap. 23, Vila Guarani. CEP: 04313-210. São Paulo, SP.

Recebido 02/07/2012, 1a Reformulação 08/04/2013, Aprovado 11/04/2013. 


\section{Referências}

Abdalla, I. G., Batista, S. H., \& Batista, N. A. (2008). Desafios do ensino de psicologia clínica em cursos de psicologia. Psicol.: Ciênc. e Prof., 28(4), 806-819. doi: http://dx.doi.org/10.1590/ S1414-98932008000400012

Aguilar-da-Silva, R. H., Scapin, L. T., \& Batista, N. A. (2011). Avaliação da formação interprofissional no ensino superior em saúde: aspectos da colaboração e do trabalho em equipe. Avaliação (Campinas) 16(1), 165-184. doi: http://dx.doi. org/10.1590/S1414-40772011000100009

Barr, H. (1989). Competent to collaborate towards a competencybased model for interprofesional education. Journal of Interprofessional Care, 12(2), 81-188.

Benevides, R. A. (2005, maio/ago.) Psicologia e o Sistema Único de Saúde: quais interfaces? Psicologia \& Sociedade, 17(2), 21-25. doi: http://dx.doi.org/10.1590/S010271822005000200004 .

Bock, A. M. B. (1999). A psicologia a caminho do novo século: identidade profissional e compromisso social. Estudos de Psicologia, 4(2), 315-329. doi: http://dx.doi.org/10.1590/ S1413-294X1999000200008

Brasil. Ministério da Educação. (2003). Conselho Nacional de Educação/Câmara de Educação Superior (CNE/CES). Parecer no $\mathrm{CNE} / \mathrm{CES}$ no $67 / 2003$.

Brasil. Ministério da Educação. (2004). Conselho Nacional de Educação. Câmara de Educação Superior. Parecer CNE/CES 0062/2004 de 19 de fevereiro de 2004. Diretrizes curriculares nacionais para o curso de graduação em Psicologia. Recuperado em 17 de jun. 2004 de http://www.abepsi.org. br/abepsi/linha_do_tempo/memoria/docs/fr_2004_2.htm.

Center for the Advancement of Interprofessional Education (CAIPE) Interprofessional education - a definition. Recuperado em 5 de abril de 2007 de http://www.caipe.org.uk/ .

Campos, G. W. S., \& Amaral, M. A. (2007). A clínica ampliada e compartilhada, a gestão democrática e redes de atenção como referenciais teórico-operacionais para a reforma do hospital. Ciênc. Saúde Coletiva (online) 12(4) , 849-859. doi: http://dx.doi.org/10.1590/S1413-81232007000400007

Champion, M., \& Haywar, M. (2006). Evaluation of a shared learning exercise involving clinical psychology trainees and dietetic students. Recuperado em 12 de outubro 2011 de http://www.psychology.heacademy.ac.uk/docs/pdf/ p20060217_Shared_learning_Case_study_for_MHHE.pdf

Ferreira Neto, J. L. (2010). A atuação do psicólogo no SUS: análise de alguns impasses. Psicol.: Ciênc. e Prof., 30(2), 390-403. doi: http://dx.doi.org/10.1590/S1414-98932010000200013

Guirado, M. (1987). A psicologia institucional de Bleger. In M. Guirado. Psicologia institucional. São Paulo: E. P. U.

Howell, D. M. (2009). The process of interprofessional teamwork between occupational therapy and psychology students. Recuperado em 12 de outubro, 2011 dehttp:// www.cabhalifax2009.dal.ca/Files/Abstracts_by_Surname/ Howell,_Dana_M._-_The_Process_of_Interprofessional_ Teamwork.pdf.

Landim, S., Silva, G.T.R, \& Batista, N.A. (2012, jan./abr.) Residência multiprofissional em saúde da família: vivência hospitalar dos enfermeiros. Revista Baiana de Enfermagem, Salvador, 26(1), 375-386.
Levison, D. A. (2003, fev.). CHMS position paper: Interprofessional education. Recuperado em 27 de maio de 2012 de Council of Heads of Medical Schools http://www.medschools.ac.uk/ AboutUs/Projects/Documents/Interprofessional\%20Education. pdf

Mângia, E. F. (2009, jan./abr.). Aprender junto para trabalhar junto: o desafio da formação para o trabalho interprofisional. Rev. Ter. Ocup., 20(1), i-ii. doi: http://dx.doi. org/10.11606\%2Fissn.2238-6149.v20i1 pi-ii

Mazer, S. M., \& Melo-Silva, L. L. (2010). Identidade profissional do psicólogo: uma revisão da produção científica no Brasil. Psicol.: Ciênc. e Prof., 30( 2), 276-295. doi: http://dx.doi. org/10.1590/S1414-98932010000200005

McNair, R. (2005, maio). The case for education health care students in professionalism as the core content of interprofessional education. Medical Education, 39(5), 456464. doi: 10.1111/j.1365-2929.2005.02116.x

Marconi, M. A., \& Lakatos, E. M. (2003). Fundamentos de metodologia científica (5a ed.). São Paulo: Atlas.

Minayo, M. C. S. (2007). O desafio do conhecimento: pesquisa qualitativa em saúde (10a ed.). São Paulo: Hucitec/Abrasco.

Parsell, G., \& Bligh, J. (1999). The development of a questionnaire to assess the readiness of health care students for interprofessional learning (RIPLS). Medical Education, 33(2), 95-100.

Universidade Federal de São Paulo (2006). Projeto Político Pedagógico: a educação interprofissional na formação em saúde; a competência para o trabalho em equipe e para a integralidade no cuidado. Campus Baixada Santista, SP. Recuperado em 12 de outubro 2011, de http://prograd. unifesp.br/santos/download/2006/projetopedagogico.pdf.

Robinson, L. M., Church, E., \& Goodwin, J. (2009). The role of psychology in interprofessional education and practice. Recuperado em 12 outubro, 2011 de http:// www.cabhalifax2009.dal.ca/Files/Abstracts_by_Surname/ Robinson,_Lynne1.pdf

Severo, S. B., \& Seminotti, N. (2010, jun.). Integralidade e transdisciplinaridade em equipes multiprofissionas na saúde coletiva. Ciênc. Saúde Coletiva, 15(Supl. 1), 1685-1698. doi: http://dx.doi.org/10.1590/S1413-81232010000700080

Spink, M. J. P., Bernardes, J. De S., \& Menegon, V. S. M. et al. (2006). A psicologia em diálogo com o SUS: prática profissional e produção acadêmica. (Relatório de pesquisa). Recuperado em 02 maio, 2009 de htpp://www.abepsi.com.br.

World Health Organization. (1978, sept.). Alma-Ata 1978: Primary health care. Report of the International Conference on Primary Health Care. Alma-Ata, USSR; Geneva: World Health Organization.

World Health Organization. (1988). Learning together to work together for health. Report of a WHO study group on multiprofessional education for health personnel: The team approach. (Technical report series 769, 1-72). Geneva: World Health Organization. 